\title{
Design \& Air Flow Simulation of Small Scale Working Model Of Hovercraft
}

\author{
A. V. Kale, A. J.Ghogare, R. N.Yerrawar, P.B. Biradar \\ (Department of Mechanical Engineering, M.E.S College of Engineering, S. P. Pune University, India)
}

\begin{abstract}
Hovercraft is an air cushion vehicle which moves on the land, ice, water and several other surfaces on which other vehicle cannot travel like in mud. The main focus is on applying the basic principles, laws and equations like continuity, energy, momentum for simulating the model. The simulation of the model is done to optimize the lift of hovercraft by optimize flow pattern and by finding dimensions and other parameters like pressure, velocity, discharge for particular weight. This paper is prepared regarding to work of simulation and design of small scale working model of hovercraft. Before the actual simulation basic theory is studied various methodologies and basics regarding to software as well as for project concern are studied. The result obtained from simulation is studied and optimum flow pattern for particular weight is selected in order to design the actual model. The results obtained by simulation are compared with the result obtained from the experimental model of hovercraft. This paper is regarding to work of simulation and comparison with theoretically calculated values.
\end{abstract}

Keywords: CFD (Computational Fluid Dynamics), hovercraft, simulation

\section{INTRODUCTION}

Hovercraft is an Air cushion vehicle that can move on the water, land, ice. Hovercraft works on the two basic principles lift and thrust. According to Archimedes's principle the pressurized air is greater than the weight of the body its starts to lift [1]. The central fan as shown in Fig.1 is use to obtain the lift by directing proper amount of air downwards. It is able to operate in all types of climates. It is mostly used for transportation purpose. It is also called as 'Air Cushion Vehicle'. To create lift and maintaining stability fan and the skirt of elastic material is used. Forward movement is obtained by air propeller. The air pressure inside the flexible skirt called cushion enables the hovercraft to lift and move smoothly on the various surfaces. The pressure inside the cushion needs to be maintain all the time while lift fan capable to operate in the long duration to ensure hovercraft can move forward at required speed. The pressurized air escaping through passage reduces the friction between the surface that has direct contact with the skirt and thereby can attain higher speeds. Skirt is made of suitable material like fabric, nylon urethane coating, vinyl coated nylon, and neoprene coated nylon. Previously lot much work is done on the various parts like skirt, load distribution, design, cushioning materials etc. our project is in concern with the simulation in order to optimize the lift of the hovercraft. Basic working principle, methodology and component selection as well as its application in transportation is studied [1]. Study of lift system, propelling system, and steering system is done to build a hovercraft. The basic consideration required for the calculations are taken out. Momentum curtain theory and Plenum chamber through which the flow takes place is studied [2].

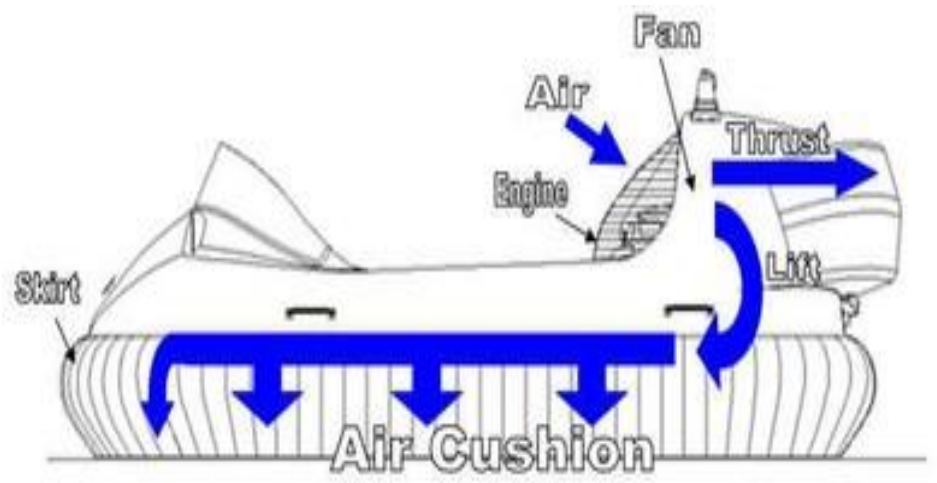

Fig.1 Basic working principle 
Details theoretical study is done for successful propulsion of hovercraft. Components, basic functions and calculations of lift system, thrust system, steering system is done to obtain the necessary parameters [3]. Major work on the design of components, selection of skirt materials for cushioning is done. Calculations are done by using simple laws and principles such as Bernoulli's equation, continuity equation [4].

\section{ANALYTICAL METHOD}

Total weight of the hovercraft including weight of the component as well as weight to lift=1 $\mathrm{kg}$ [4].

For maximum stability of the hovercraft dimensional parameters are found assuming [4]

Length: width $=2: 1$

Height: width $=0.7: 1$

Length $=200 \mathrm{~mm}$, width $=100 \mathrm{~mm}$, height $=70 \mathrm{~mm}$, hover gap $($ lift $)=10 \mathrm{~mm}$, diameter of fan $=70 \mathrm{~mm}$

Perimeter $=2(0.2+0.1)=0.6 \mathrm{~m}$

From Bernoulli's equation (conservation of energy) neglecting losses we get,

Pressure $\mathrm{Pr}=\mathrm{W} / \mathrm{A}, \mathrm{P}=9.81 / 0.2 \times 0.1$,

$\mathrm{Pr}=490 \mathrm{~N} / \mathrm{m}^{2}$

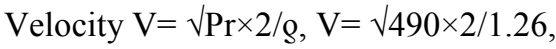

$\mathrm{V}=27 \mathrm{~m} / \mathrm{s}$

Escaping area $=2(0.2+0.1) \times 0.01$

$\mathrm{A}=0.006 \mathrm{~m}^{2}$

From continuity equation, [4]

Discharge $=$ Velocity $\times$ Area, $Q=27 \times 0.006$

$\mathrm{Q}=0.162 \mathrm{~m}^{3} / \mathrm{s}$

Power $=$ Pressure $\times$ Discharge, $\mathrm{P}=490 \times 0.162$

$\mathrm{P}=80$ Watts

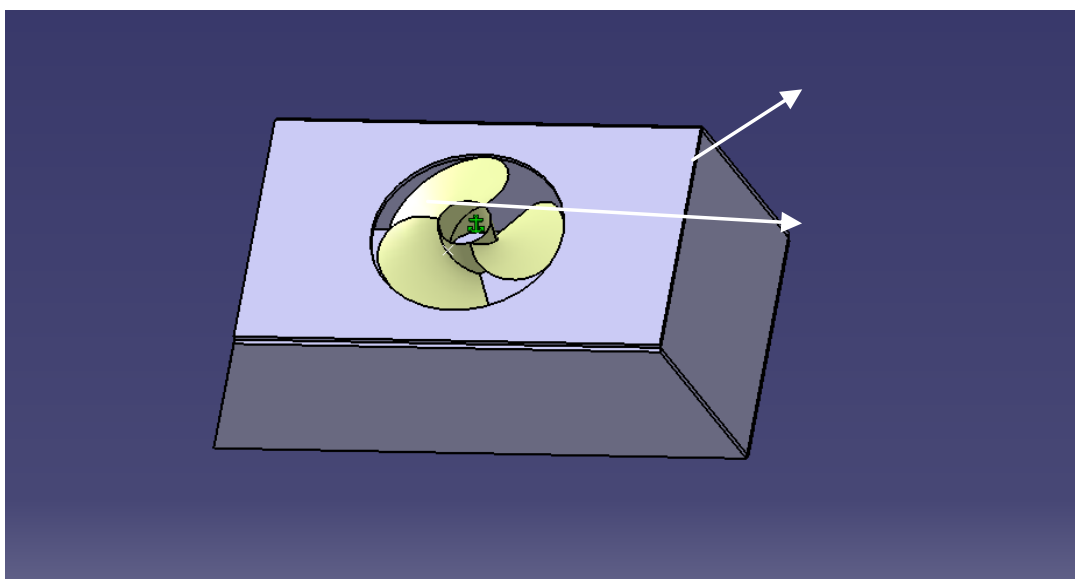

Fig.2 CAD (CATIA) model of hovercraft

The basic 3D model of hovercraft shown in Fig. 2 is made in the CATIA (modeling software). it is simple, common, user-friendly, widely used in the industry. The dimensions are calculated from the basic laws and principles. It also having advantage that it is easy to read CATIA STP files in the Ansys fluent. The capabilities of CATIA and its range allow it to use in the various field of design such as aerospace and many more diverse products.

\section{Simulation Procedure :}

For simulation of small scale CAD model of hovercraft as shown in Fig. 2 the tool Ansys fluent (CFD) software is used. Computation fluid dynamics is the analysis of system involving fluid flow, heat transfer, etc by means of computer based simulation. This technique is very powerful more precise and accurate for complex problems at topmost level. It has wide range of applications in various field like aerodynamics, aircrafts etc.The Finite Volume Method (FVM) is a common approach used in CFD codes, as it has an advantage in memory usage and solution speed, especially for large problems, turbulent flows, In the FVM, the governing partial 
differential equations (typically the Navier-Stokes equations, the mass and energy conservation equations, and the turbulence equations) are recast in a conservative form, and then solved over discrete control volumes.

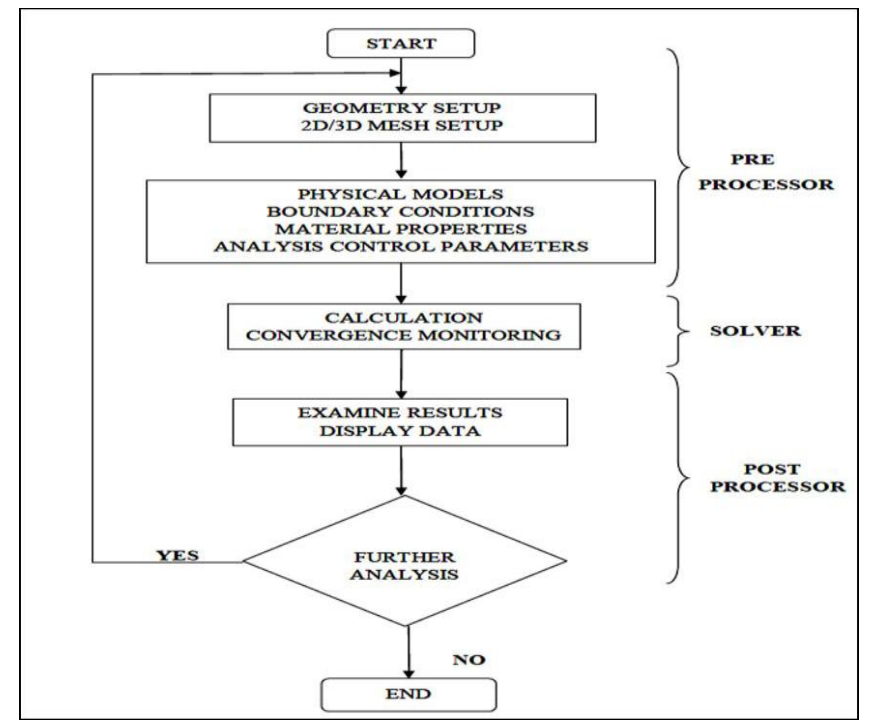

Fig.3 Flow chart for CFD analysis

\section{CFD MESHING DETAILS}

Table 1 Detail conditions used in CFD analysis

\begin{tabular}{|c|c|}
\hline Material type & Fluid \\
\hline Fluent fluid materials & Air \\
\hline Density & Air \\
\hline Operating pressure & 416 Pascal \\
\hline Body material & Wood \\
\hline Velocity & $9 \mathrm{~m} / \mathrm{s}$ \\
\hline Energy Equation & On \\
\hline Nodes & 41180 \\
\hline No. of Elements & 389850 \\
\hline Type of mesh & Tetrahedron \\
\hline
\end{tabular}

As shown in Figs.4-5 the basic model is generated in the Ansys fluent by considering the parameters and conditions as shown in the Table 1 . The selection of various parameters is based on the model material, type of fluid, boundary conditions. The determination of element size, number of elements is done according to literature. As the software is more versatile, quite accurate to complex solutions Ansys fluent (CFD) is selected to obtain the results.

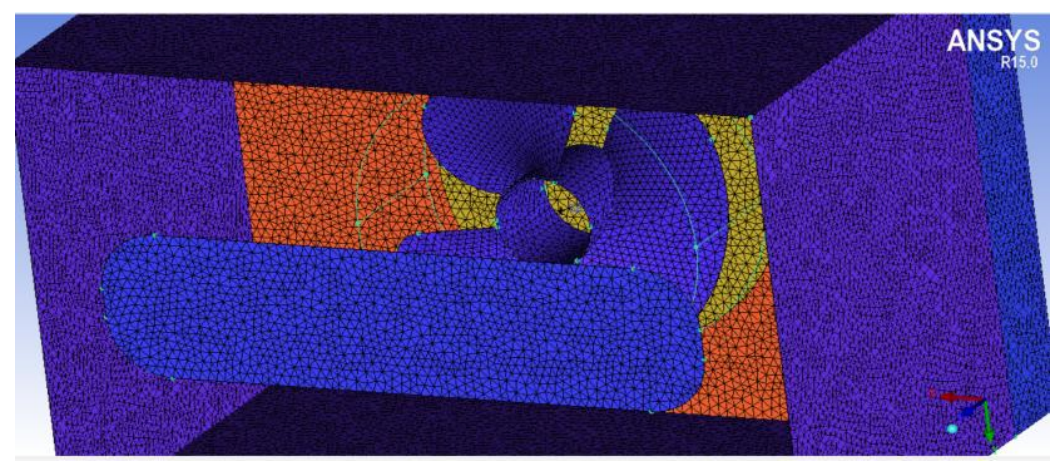

Fig. 4 mesh model of hovercraft 


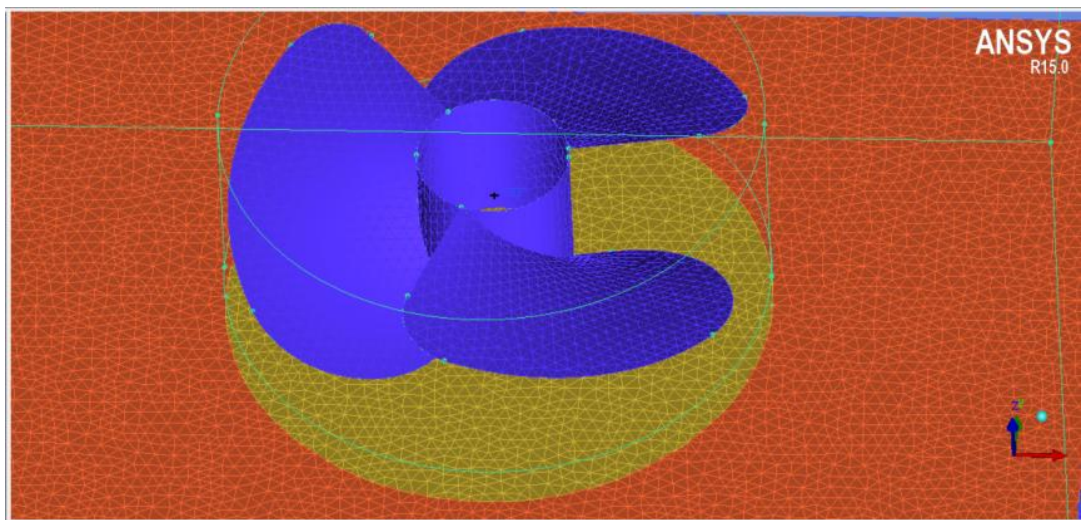

Fig.5 meshed model of hovercraft

\section{RESULTS AND DISCUSSION}

The objective of this research work is to optimize the lift of hovercraft through proper study of flow, velocity and pressure distribution. The attempt has been made to compare the analytical results with the simulation results as shown in Table2. Velocity of escaping air is obtained at particular location is shown by Fig.6. This shows the velocity vectors colored by velocity magnitude. The value of velocity for optimum flow is $21 \mathrm{~m} / \mathrm{s}$ is selected. The Fig.7 shows the path lines colored by velocity magnitude. From Fig. 8 the magnitude of velocity is obtained in the flow field inside the body of the hovercraft. The Fig.9 gives the contours of static pressure. Also other parameters are found out.

Table 2 Comparison of result

\begin{tabular}{|c|c|c|c|}
\hline Sr. No & Parameters & Analytical & Numerical \\
\hline 1 & velocity & 27 & 21.13 \\
\hline 2 & pressure & 490 & 464 \\
\hline
\end{tabular}

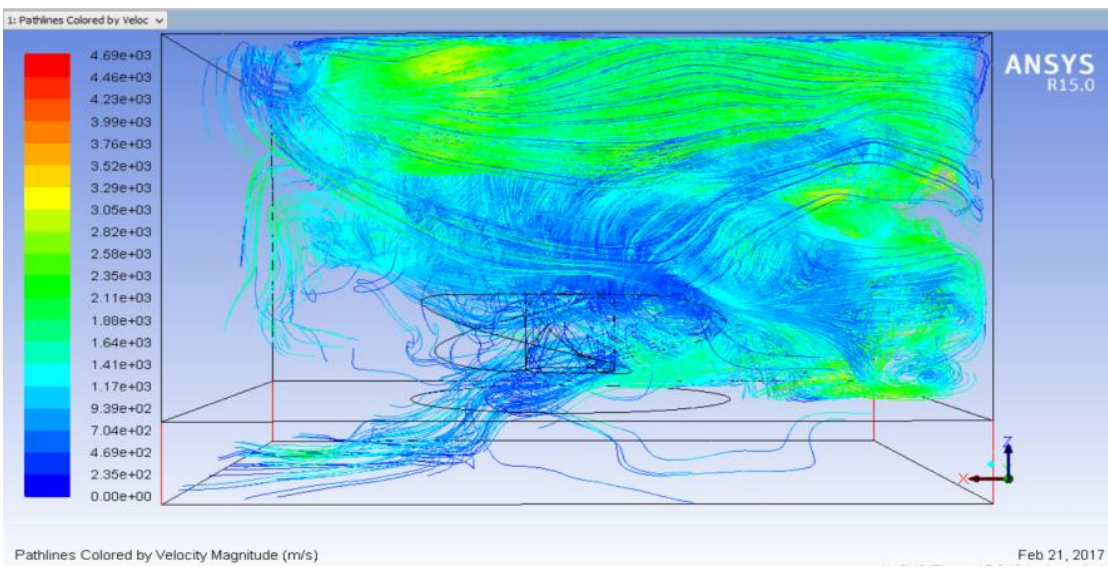

Fig. 6 Path lines

\section{CONCLUSION}

From above simulation results we conclude that for given weight of hovercraft the values obtained by simulation are closer to the values obtained from theoretical calculations. From this the best suited dimensions as well as the optimum pressure, velocity, discharge also obtained. The velocity distribution and pressure distribution is also studied. body parts instead of making separately are made integral then the performance of the hovercraft considerably increases by reducing the power consumption. The difference in the numerical values and the analytical values of velocity and pressure is due to air required for cushioning is not considered in the numerical calculations 


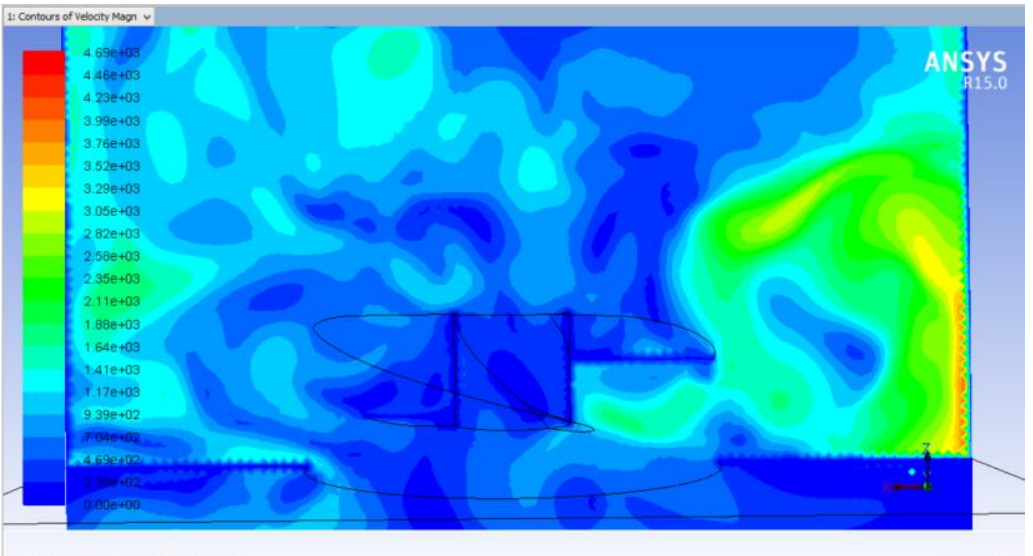

Contours of Velocity Magnitude ( $m / s)$ Feb 21, 201
ANSYS Fluent 150 (3d, pbns, rle

Fig. 7 Contours of velocity
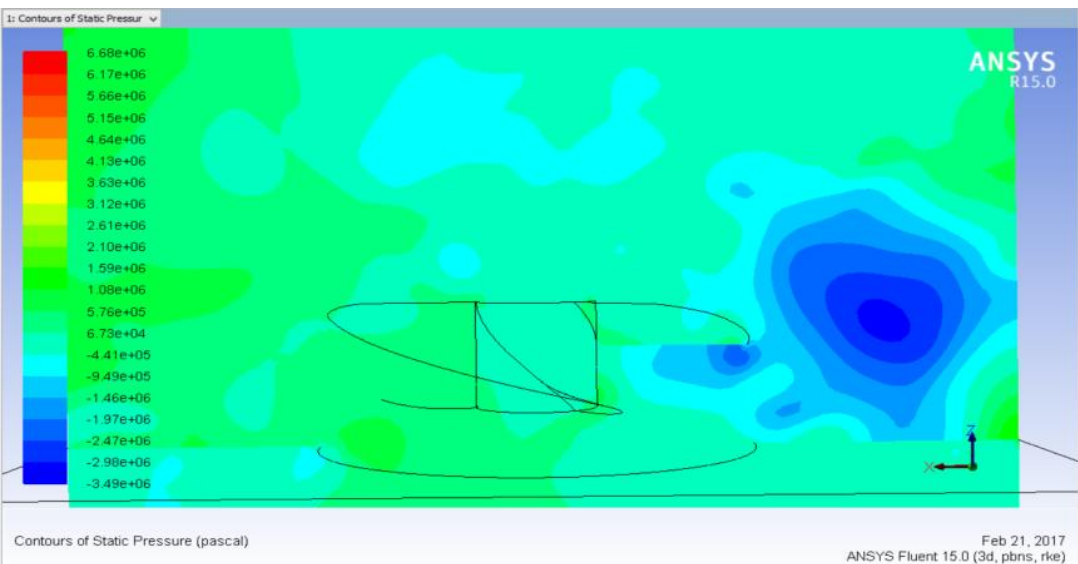

Fig. 8 Contours of static pressure

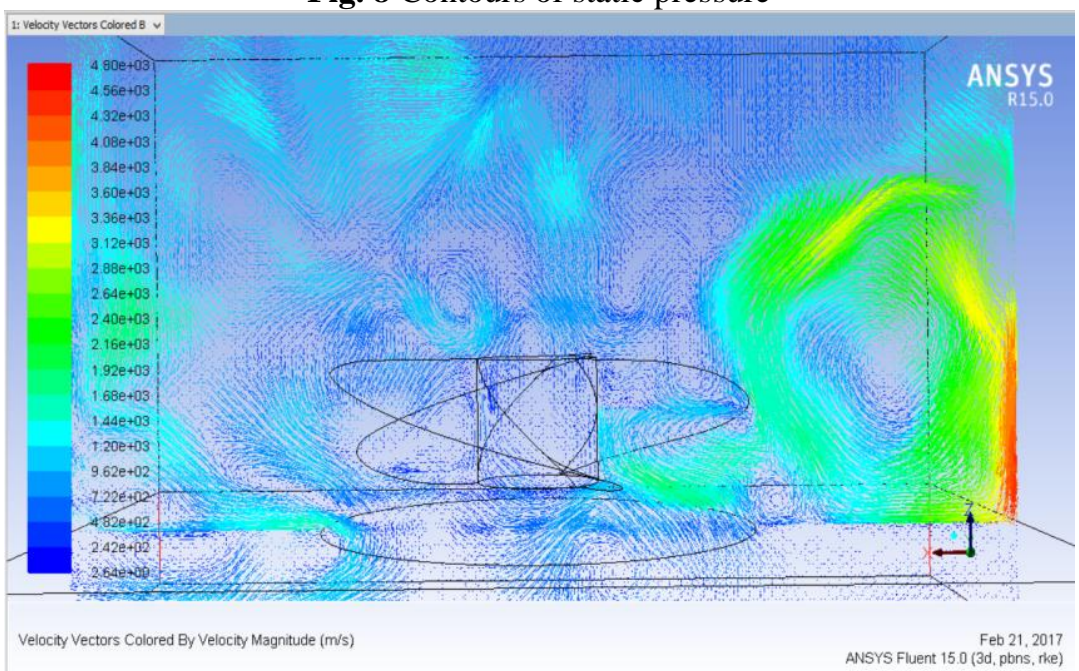

Fig. 9 Velocity vectors

\section{REFERENCES}

[1]. A.Tiwari, To Study And Fabrication Of Air Cushion Vehicle, Scholar, Pacific University Udaipur Rajasthan, India international journal of research -granthaalayah, 3(3),2015

[2]. V Abhiram, N Sunman Krishna, T Murali Mohan Raju and M Anjiah ,Study On Construction And Working Principle Of A Hovercraft, International journal of mechanical engineering and robotics research ISSN $2278-$ 0149,3(4),2014. 
[3]. Okafor,Development of A Hovercraft Prototype, Fed. University of Technology., Owerri-Nigeria.International Journal of Engineering and Technology, 3(3), 2013

[4]. S.V. Uma Maheswara Rao, V.S. Surya Prakash (Professor, M.E Student, Department of Marine Engineering, AUCE (A), Visakhapatnam-5300003)Development Of An Integrated Air Cushioned Vehicle (Hovercraft), International Journal of Modern Engineering Research (IJMER), 4(5),2014, 21.

[5]. ZheLuo, Jig Chen and Bing-Cong chen published paper on Study Of Load Distribution For A Semi- Tracked Air Cushion Vehicle,SAE ,Journal of commertial vehicles, 108-2,2014

[6]. P.Vasanthkumar, K.Vighesh,G.Rajkumar,Design and Fabrication of Mini hovercraft, International journal of innovative research in science, engineering and technology, 4,2015.

[7]. A.K.Amiruddin, S.M.Sapuan, and A.A.Jaafar, Development of a hovercraft prototype with an aluminum hull base. International Journal of the Physical Sciences, 6(17), 2011, 4185-4194. 